\title{
Real-World Hypertension Prevalence, Awareness, Treatment, and Control in Adult Diabetic Individuals: An Italian Nationwide Epidemiological Survey
}

\author{
Martina De Feo ${ }^{1} \cdot$ Rita Del Pinto $^{1}$ (D) Silvia Pagliacci ${ }^{2}$. Davide Grassi ${ }^{1} \cdot$ Claudio Ferri $^{1}$ on behalf of The Italian Society \\ of Hypertension and Federfarma
}

Received: 18 February 2021 / Accepted: 25 March 2021 / Published online: 9 April 2021

(c) The Author(s) 2021

\begin{abstract}
Introduction Hypertesion is the leading cause of morbidity and mortality, worldwide, and its prevalence has been increasing in several countries, including Italy.

Aims To assess hypertension prevalence, awareness, treatment, and control in a real-world sample of adults with self-reported diabetes compared with nondiabetic individuals.

Methods Following the 2018 World Hypertension Day, a nationwide, cross-sectional epidemiological survey on cardiovascular risk factors ("Abbasso la Pressione!") in 3956 Italian pharmacies enrolled 47217 self-presenting volunteers ( $\geq 18$ years). Participants underwent standardized blood pressure (BP) measurements and answered a questionnaire on cardiovascular risk factors and lifestyle habits. Questions included if they had an established diagnosis of diabetes, hypertension or were on a BP medication. Hypertension prevalence was defined as systolic BP $\geq 140$ and/or diastolic BP $\geq 90 \mathrm{mmHg}$. A double definition for hypertension control based on the recent European and US guidelines on hypertension was applied.

Results Diabetic individuals $(\mathrm{N}=5695,12 \%)$ had higher rates of hypertension prevalence $(80 \%$ vs. $54.7 \%, \mathrm{p}<0.001)$, awareness $(85.6 \%$ vs $77.3 \%, \mathrm{p}<0.001)$ and treatment $(85.8 \%$ vs. $76.7 \%, \mathrm{p}<0.001)$, but lower hypertension control rates ( $36.1 \%$ vs. $39.6 \%$ according to the 2018 European guidelines, $\mathrm{p}<0.001 ; 25.4 \%$ vs $30.8 \%$ according to the 2017 US guidelines, $\mathrm{p}<0.001$ ) than nondiabetics. Diabetic participants tended to be older, sedentary, overweight/obese, dyslipidemic men, with higher 10-years cardiovascular risk than nondiabetics $(\mathrm{p}<0.001)$. Uncontrolled hypertension was associated with male gender, diabetes, body mass index, unhealthy lifestyle habits, and older age.

Conclusions Elevated hypertension awareness and treatment rates in diabetic adults do not translate into adequate BP control in the real world. Concomitant unfavorable metabolic features and unhealthy lifestyle habits might contribute to this observation.
\end{abstract}

Keywords Aspects of diabetes $\cdot$ Arterial hypertension $\cdot$ Awareness $\cdot$ Control $\cdot$ Population survey

Martina De Feo and Rita Del Pinto equally contributed.

Martina De Feo and Rita Del Pinto are members of the Young Investigators Study Group of the Italian Society of Hypertension.

Claudio Ferri Past-President of the Italian Society of Hypertension.

Italian Society of Hypertension Collaborators members are listed in the Acknowledgements section.

Rita Del Pinto

rita.delpinto@univaq.it

Extended author information available on the last page of the article

\section{Introduction}

Hypertension is an independent risk factor for cardiovascular diseases (CVD) [1]. Its prevalence is estimated at around $30 \%$ of the adult population in industrialized countries, but it becomes even more common in the presence of diabetes mellitus [2]. The simultaneous presence of diabetes and hypertension accelerates the development of micro- and macrovascular complications and further increases cardiovascular risk by at least fourfold compared with the absence of these conditions [2].

In keeping with this, data from the Framingham Heart Study showed that individuals with concomitant diabetes 
and hypertension exhibited higher rates of all-cause mortality (32 against 20 for 1000 people-year, $\mathrm{p}<0.001$ ) and cardiovascular events (52 versus 31 for 1000 people-year; $\mathrm{p}<0.001)$ than diabetic individuals with normal blood pressure (BP), suggesting that the exceeding burden of disease in the former was largely attributable to hypertension [3]. The intensity of care and related costs for comorbid hypertension and diabetes are not additive: indeed, they exceed those related to the separate management of the diseases $[4,5]$.

In parallel, hypertension control rates remain globally unsatisfactory for the standard of high-quality hypertension programmes [6]. In fact, despite a substantial improvement compared with the 1980s, treatment coverage and control rates for hypertension have settled at best around $80 \%$ and 60-70\%, respectively, since mid-2000s [6-8]. Several physiopathological and management-related factors, including application and adherence to pharmacological and non-pharmacological strategies for the management of hypertension, make adequate BP control achievement even more challenging in the presence of diabetes [9-12]. In consideration of the elevated socioeconomic burden and the relevant use of healthcare resources, the detection of hypertension and factors related to BP control among individuals with diabetes is a public health priority.

We analyzed data from a nationwide, cross-sectional epidemiological survey conducted in 3956 Italian pharmacies during the 2018 World Hypertension day to assess realworld hypertension prevalence, awareness, treatment, and control rates among individuals with self-reported diabetes compared with nondiabetic participants.

\section{Methods}

\subsection{Data Source}

Abbasso la Pressione! (May 17-20, 2018) was a 4-days, nationwide, cross-sectional epidemiological Italian survey co-sponsored by the Italian Society of Hypertension (SIIA) in collaboration with the National Federation of Italian Pharmacies (Federfarma) following the World Hypertension Day in 2018 [13]. It involved 3956 pharmacies (21\% of total) throughout the national territory with the aim of estimating prevalence and awareness of modifiable/non-modifiable cardiovascular risk factors, with particular focus on hypertension, among self-presented adult customers ( $\geq 18$ years) who consented to participate. Participation was completely voluntary, and signed informed consent was obtained from each participant. The survey and related research fulfill the principles stated in the Declaration of Helsinki.

\subsection{Data Collection}

Self-presenting participants who consented to participate underwent 3 standardized BP measurements according to guidelines protocol [1] and answered a questionnaire on cardiovascular risk factors and lifestyle habits. BP was measured for each participant after 2 minutes rest, in sitting position, by trained pharmacists using an automated oscillometric device, and the average of the second and third measurements was used for the analysis. The questionnaire included if they had an established diagnosis of diabetes (irrespective of diabetes type), hypertension, or were on a BP medication. Self-reported anthropometric data (age, height, weight) were expressed as numeric variables. Additional modifiable (smoking; sedentary lifestyle in terms of $<30$ minutes/day of physical activity; hypercholesterolemia) and unmodifiable (gender; family history of CVD) cardiovascular risk factors, dietary habits (unlimited use of dietary salt; everyday consumption of fruit and vegetables), as well as the presence of established CVD and chronic kidney disease (CKD) were expressed as categorical data. BMI was calculated based on self-declared weight and height. The 10-year cardiovascular risk was derived according to guidelines [14]. Geographic provenance was recorded automatically.

\subsection{Statistical Analysis}

Diabetic status was defined as being diabetic or nondiabetic based on self-reported information. BP was treated as both a numeric value $(\mathrm{mmHg})$ and a categorical variable (i.e BP status, expressed as: controlled/uncontrolled hypertension; and BP categories, expressed as: optimal, normal, or high normal BP, grade 1-2-3 hypertension, and isolated systolic hypertension) [15]. Based on the 2017 American College of Cardiology/American Heart Association (ACC/ AHA) Guidelines for the management of arterial hypertension [1], the diagnostic threshold for hypertension was BP $\geq 140$ and/or $90 \mathrm{mmHg}$, while the BP target was $<130 / 80$ $\mathrm{mmHg}$ for both diabetic and nondiabetic participants. An additional definition of controlled hypertension was also tested, based on the 2018 European Society of Cardiology/ European Society of Hypertension (ESC/ESH) guidelines for the management of hypertension $(<130 / 80 \mathrm{mmHg}$ in treated participants $<65$ years, and $<140 / 80 \mathrm{mmHg}$ if $\geq 65$ years) [15]. Hypertension prevalence rate was defined based on measured BP values above the specified threshold among individuals not receiving antihypertensive medications, or as being on antihypertensive drugs. Hypertension awareness rate was defined as the proportion of participants with prevalent hypertension who reported having been diagnosed, while hypertension treatment rate was defined as the proportion of participants with prevalent hypertension who 
were using medication to treat this condition. Hypertension control rate among individuals on antihypertensive treatment was defined as having BP values below the previously specified target. Hypertension treatment and control rates and $95 \%$ confidence intervals (CI) were evaluated according to diabetic status, and the likelihood estimate for the difference between participants with and without diabetes was evaluated using Yates correction for continuity.

The age- and gender-adjusted odds ratio (OR) and relative 95\% CI for the association between diabetic status (dependent variable) and hypertension (independent variable) was assessed by logistic regression. An additional model was fitted to investigate the association of uncontrolled hypertension (dependent variable) with selected risk factors (independent covariates).

Differences in participants' characteristics were evaluated with unpaired $t$ tests for continuous variables (mean \pm standard deviation, $\mathrm{SD}$ ) and $\chi^{2}$ tests for categorical variables
$(\mathrm{N}, \%)$. Statistical analyses were performed using R (v 4.0.2)

[16]. Statistical significance was set at $\mathrm{p}<0.05$.

\section{Results}

\subsection{General Characteristics of the Sample}

Of 47217 participants enrolled in the project, $12.1 \%$ $(\mathrm{N}=5695)$ had diabetes. Clinical and demographic characteristics by diabetes status are summarized in Table 1 .

Compared with nondiabetic participants, individuals with diabetes tended to be older, overweight/obese, dyslipidemic men, with greater prevalence of family/personal history of CVD/CKD, higher mean systolic BP $(136.0 \pm 18.4 \mathrm{mmHg}$ versus $128.3 \pm 17.8 \mathrm{mmHg}, \mathrm{p}<0.001)$ and higher 10 -year cardiovascular risk (Table 1). Diabetic individuals were more sedentary and were less likely to report a regular use of fruits/vegetables than nondiabetics. In parallel, they also
Table 1 Demographic, clinical and lifestyle characteristics of survey participants with and without diabetes

\begin{tabular}{|c|c|c|c|}
\hline & Diabetic participants & Nondiabetic participants & p-value \\
\hline $\mathrm{N}$ & 5695 & 41,522 & \\
\hline Men (\%) & $2794(49.1)$ & $15,820(38.1)$ & $<0.001$ \\
\hline Age category, years (\%) & & & $<0.001$ \\
\hline$<35$ & $135(2.4)$ & $3267(7.9)$ & \\
\hline $35-44$ & $249(4.4)$ & 4819 (11.6) & \\
\hline $45-64$ & $1821(32.0)$ & $17,854(43.0)$ & \\
\hline$\geq 65$ & $3490(61.3)$ & $15,582(37.5)$ & \\
\hline SBP, mmHg (mean, SD) & $136.0 \pm 18.4$ & $128.3 \pm 17.8$ & $<0.001$ \\
\hline $\mathrm{DBP}, \mathrm{mmHg}$ (mean, SD) & $76.8 \pm 11.4$ & $76.7 \pm 10.7$ & 0.366 \\
\hline BMI category (\%) & & & $<0.001$ \\
\hline Underweight & $42(0.7)$ & $975(2.3)$ & \\
\hline Normal & $1591(27.9)$ & $18,932(45.6)$ & \\
\hline Overweight & $2335(41.0)$ & $15,133(36.4)$ & \\
\hline Obesity I & $1264(22.2)$ & $5075(12.2)$ & \\
\hline Obesity II & $330(5.8)$ & $1114(2.7)$ & \\
\hline Obesity III & $133(2.3)$ & $293(0.7)$ & \\
\hline Dyslipidemia (\%) & $2686(47.2)$ & $12,636(30.4)$ & $<0.001$ \\
\hline CVD/CKD (\%) & $1495(26.3)$ & $4613(11.1)$ & $<0.001$ \\
\hline 10-years CV risk (\%) & & & $<0.001$ \\
\hline$\leq 2 \%$ & $0(0.0)$ & $29,269(70.6)$ & \\
\hline $3-9 \%$ & $4155(72.9)$ & $7640(18.4)$ & \\
\hline$\geq 10 \%$ & $1540(27.1)$ & $4613(11.0)$ & \\
\hline Familiar history of CVD (\%) & $2394(42.0)$ & $15,534(37.4)$ & $<0.001$ \\
\hline Salt use (\%) & $1436(25.2)$ & $11,124(26.8)$ & 0.012 \\
\hline Fruits/vegetables use (\%) & $4504(79.1)$ & $33,665(81.1)$ & $<0.001$ \\
\hline Physical activity (\%) & $2397(42.1)$ & $19,254(46.4)$ & $<0.001$ \\
\hline Cigarette smoking (\%) & $1122(19.7)$ & $8420(20.3)$ & 0.318 \\
\hline
\end{tabular}

Chi-squared test and Student's t test are applied, as appropriate $S B P$ systolic blood pressure, $D B P$ diastolic blood pressure, $B M I$ body mass index, $C V D$ cardiovascular disease, $C K D$ chronic kidney disease 
reported making less use of salt than the counterpart. No difference in diastolic BP and smoking habits was recorded by diabetic status.

\subsection{Hypertension Prevalence, Awareness, Treatment, and Control}

Hypertension prevalence, awareness, treatment, and control rates by diabetic status are summarized in Table 2. Hypertension prevalence was $80 \%(\mathrm{~N}=4556)$ among diabetic individuals and $54.7 \%(\mathrm{~N}=22,733)$ among nondiabetics $(\mathrm{p}<0.001)$. The age- and gender-adjusted OR $(95 \% \mathrm{CI})$ for concomitant diabetes and hypertension was 2.28 (95\% CI 2.12-2.46; $\mathrm{p}<0.001$ ).

Awareness of hypertension was $85.6 \%$ (95\% CI $84.6-86.6 ; \mathrm{p}<0.001)$ in diabetic individuals and $77.3 \%$ $(95 \%$ CI $76.8-77.9 ; p<0.001)$ in nondiabetics. The likelihood estimate for the difference between groups was $8.3 \%$ (95\% CI 7.2-9.5; $\mathrm{p}<0.001)$.

Among those with prevalent hypertension, 3910 individuals with diabetes and 17446 of nondiabetics reported using antihypertensive medications, with hypertension treatment rates of $85.8 \%$ (95\% CI 84.8-86.8; p < 0.001) and 76.7\% (95\% CI 76.2-77.3; $\mathrm{p}<0.001$ ), respectively. The likelihood estimate for the difference between groups was $9.1 \%$ (95\% CI 7.9-10.2; $\mathrm{p}<0.001)$.

Among those with treated hypertension, 994 individuals with diabetes and 5366 of nondiabetics had controlled hypertension according to the $2017 \mathrm{ACC} / \mathrm{AHA}$ hypertension guidelines, with hypertension control rates of $25.4 \%$ (95\% CI $24.1-26.8 ; \mathrm{p}<0.001)$ and $30.8 \%$ (95\% CI 30.1-31.4; $\mathrm{p}<0.001$ ), respectively. The likelihood estimate for the difference between groups was $-5.3 \%$ (95\% CI -6.9 to -3.8 ; $\mathrm{p}<0.001)$. Using the more recent $2018 \mathrm{ESC} / \mathrm{ESH}$ hypertension guidelines, 1410 individuals with diabetes and 6901 of nondiabetics had controlled hypertension, with hypertension control rates of $36.1 \%$ (95\% CI 34.6-37.6; $\mathrm{p}<0.001$ ) and $39.6 \%$ (95\% CI 38.8-40.3; p <0.001), respectively. The likelihood estimate for the difference between groups was $-3.5 \%$ $(95 \% \mathrm{CI}-5.2$ to $-1.8 ; \mathrm{p}<0.001)$.
The prevalence of optimal and normal BP among diabetic individuals taking or not taking antihypertensive medications was lower compared with the same strata of nondiabetics (Table 3). Conversely, the prevalence of isolated systolic hypertension among diabetic individuals taking or not taking antihypertensive medications was higher compared with the same strata of nondiabetics (Table 3).

Features associated with uncontrolled hypertension were male gender (OR 1.64, 95\% CI 1.57-1.70, $\mathrm{p}<0.001)$, cigarette smoking (OR 1.34, 95\% CI 1.27-1.40; $\mathrm{p}<0.001$ ), selfreported diabetes (OR 1.23, 95\% CI 1.15-1.31, $\mathrm{p}<0.001$ ), use of salt (OR 1.09, 95\% CI 1.04-1.14; $\mathrm{p}<0.001)$, non-use of fruits/vegetables (OR 1.09, 95\% CI 1.03-1.14, $\mathrm{p}=0.001$ ), BMI (OR 1.07, 95\% CI 1.07-1.08, $\mathrm{p}<0.001$ ), physical inactivity (OR 1.04, 95\% CI 1.00-1.09; $\mathrm{p}=0.027$ ), and age (OR $1.03,95 \%$ CI $1.02-1.03 ; \mathrm{p}<0.001$ ) (Fig. 1).

\section{Discussion}

Real-world data from more than 47000 participants in an Italian nationwide epidemiological survey on common cardiovascular risk factors indicate that individuals with self-reported diabetes had more than double the risk of comorbid hypertension, as well as higher rates of hypertension awareness and treatment, compared with nondiabetics. Nevertheless, hypertension control rates remained largely unsatisfactory, especially among individuals with diabetes. In this subset, in fact, only about one out of four individuals reached the $\mathrm{BP}$ target of $<130 / 80 \mathrm{mmHg}$. Besides diabetes and nonmodifiable demographic features, several self-reported modifiable traits were associated with uncontrolled hypertension, including cigarette smoking, excessive use of salt, poor consumption of greens, sedentary lifestyle, and excess body weight. Thus, improving clinical care of individuals with hypertension largely requires changes in lifestyle habits.

Besides sharing common contributors, including overweight, unhealthy lifestyle, and ageing, hypertension and diabetes mellitus are also strictly linked from a
Table 2 Rates of hypertension prevalence, awareness, treatment, and control by diabetic status.

\begin{tabular}{llll}
\hline & $\begin{array}{l}\text { Diabetic participants } \\
(\mathrm{N}=5,695)(\%)\end{array}$ & $\begin{array}{l}\text { Nondiabetic participants } \\
(\mathrm{N}=41,522)(\%)\end{array}$ & $\mathrm{p}$ value \\
\hline Prevalence & 80.0 & 54.7 & $<0.001$ \\
Awareness & 85.6 & 77.3 & $<0.001$ \\
Treatment & 85.8 & 76.7 & $<0.001$ \\
Control & & & $<0.001$ \\
2017 ACC/AHA guidelines & 25.4 & 30.8 & $<0.001$ \\
2018 ESC/ESH guidelines & 36.1 & 39.6 & \\
\hline
\end{tabular}

ACC/AHA American College of Cardiology/American Heart Association,ESC/ESH European Society of Cardiology/European Society of Hypertension 
Table 3 BP categories in survey participants with and without diabetes taking or not taking antihypertensive medications

\begin{tabular}{|c|c|c|c|c|}
\hline & \multicolumn{2}{|c|}{ Diabetic participants $(\mathrm{N}=5695)$} & \multicolumn{2}{|c|}{ Nondiabetic participants $(\mathrm{N}=41522)$} \\
\hline & $\begin{array}{l}\text { On HTN meds } \\
(N=3910)\end{array}$ & Untreated $(\mathrm{N}=1785)$ & $\begin{array}{l}\text { On HTN meds } \\
(\mathrm{N}=17446)\end{array}$ & Untreated $(\mathrm{N}=24076)$ \\
\hline Optimal BP, N (\%) & $516(13.2)$ & $393(22)$ & $2837(16.3)$ & $8545(35.5)$ \\
\hline Normal BP, N (\%) & $617(15.8)$ & $330(18.5)$ & $3545(20.3)$ & $5412(22.5)$ \\
\hline High normal BP, N (\%) & $861(22)$ & $416(23.3)$ & $4175(23.9)$ & $4832(20.1)$ \\
\hline Grade 1 HTN, N (\%) & $332(8.5)$ & $166(9.3)$ & $1697(9.7)$ & $1797(7.5)$ \\
\hline Grade 2 HTN, N (\%) & $207(5.3)$ & $64(3.6)$ & $733(4.2)$ & $634(2.6)$ \\
\hline Grade 3 HTN, N (\%) & $6(0.1)$ & $3(0.2)$ & $21(0.1)$ & $34(0.1)$ \\
\hline ISH, N (\%) & $1371(35.1)$ & $413(23.1)$ & $4438(25.4)$ & $2822(11.7)$ \\
\hline
\end{tabular}

All comparisons between the proportions of diabetic individuals taking or not taking antihypertensive medications with the same proportions in nondiabetic individuals were significant $(\mathrm{p}<0.05)$, except for grade 3 hypertension. Optimal BP: <120/80 mmHg; normal BP: 120-129 and/or 80-84 mmHg; high normal BP: 130-139 and/or 85-89 mmHg; grade 1 hypertension: 140-159 and/or 90-99 mmHg; grade 2 hypertension: 160-179 and/or 100-109 mmHg; grade 3 hypertension: $\geq 180$ and/or $\geq 110 \mathrm{mmHg}$; and isolated systolic hypertension: $\geq 140$ and $<90 \mathrm{mmHg}$

$B P$ blood pressure, $H T N$ hypertension, ISH isolated systolic hypertension

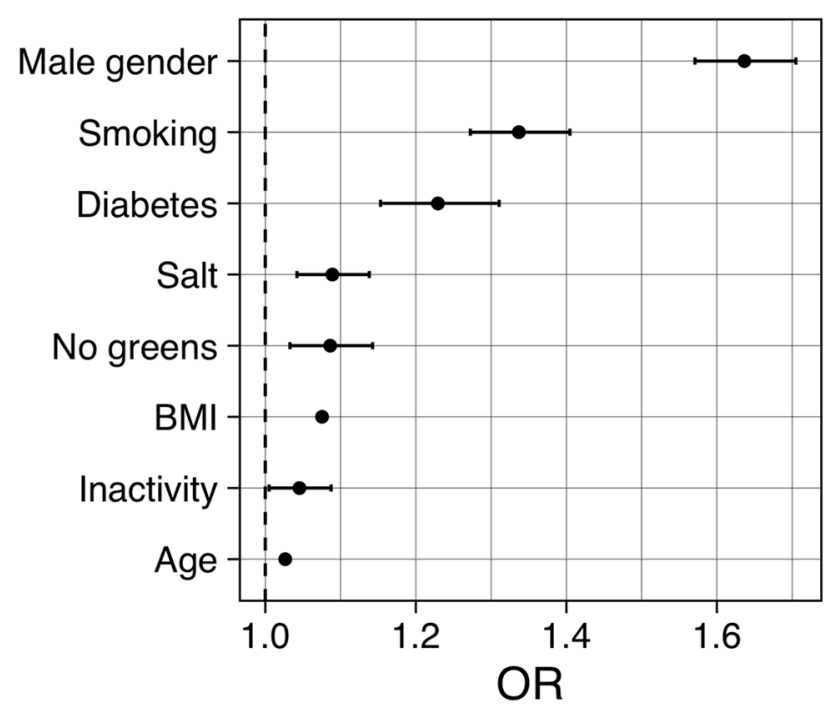

Fig. 1 Forest plot of odds ratios (OR, 95\% CI) for uncontrolled hypertension in association with selected demographic, clinical, and lifestyle features

pathophysiological point of view [17]. Insulin resistance, a common feature of both prediabetes and prehypertension [18], is associated with sodium and fluid retention. Insulin signaling can also modulate the vascular tone [19]. Other factors involved in the pathogenesis of both conditions include inappropriate activation of the renin-angiotensinaldosterone system, sympathetic imbalance, oxidative stress, inflammation, and dysfunctional immune response $[17,20]$. Furthermore, some antihypertensive drugs (e.g. thiazide diuretics) can exert unfavorable effects on the glyco-insulinemic profile [21]; in parallel, the use of certain antidiabetic medications can induce sodium and water retention, with consequent hemodynamic effects $[22,23]$.
The prevalence of hypertension by diabetic status and the risk of comorbid hypertension in the presence of diabetes that we described are similar in magnitude to those observed in a contemporary (2017-2018) cycle of the National Health and Nutrition Examination Survey (NHANES) [24]. Hypertension control rates among NHANES nondiabetic individuals $(39.01 \%, 95 \%$ CI $33.68-44.60)$ were comparable to our findings, and not dissimilar than those of NHANES diabetic individuals (40.39\%, 95\% CI 33.96-47.17) [24]. Another population-based cross-sectional survey found that treated hypertensives with diabetes were less likely to have controlled BP (OR 0.38, 95\% CI 0.25-0.58) compared with nondiabetics [25]. Altogether, real-world data indicate that attaining BP treatment goal remains a major challenge, especially when multiple cardiovascular risk factors coexist.

Although self-awareness of diabetes may be a motivation for positive interventions on modifiable risk factors, such as increasing physical activity, quitting smoking, and improving dietary habits, we did not observe differences in these features based on diabetic status, with the only exception of salt use. In parallel, the lack of hypertension awareness (14.4\% among diabetic adults, $22.7 \%$ among nondiabetics) might be one reason behind the high rates of untreated hypertension and unhealthy lifestyle habits in both groups. In this context, awareness-raising campaigns might increase the adhesion to pharmacological and nonpharmacological prevention strategies and contribute to improve diabetes care.

This study has limitations and strengths. As a cross-sectional survey, it can only describe associations, and causeeffect relationships cannot be inferred. A certain degree of selection bias, as well as the use of self-reported data, should be considered when interpreting the relative findings and might limit their generalizability. Conditions like white-coat 
hypertension and masked hypertension cannot be detected in the setting of this survey. Data on type 1 and 2 diabetes could not be segregated. Finally, data on antihypertensive medications type and doses, treatment compliance, as well as on comorbidities $[26,27]$ or socioeconomic and cultural determinants with possible impact on BP control were not available to our analysis. However, this survey was conducted on a large sample of non-institutionalized Italian population. A standardized protocol for BP measurement based on the use of automated devices was applied.

In conclusion, real-world data indicate that elevated hypertension awareness and treatment rates in diabetic individuals do not translate into adequate BP control. Concomitant unfavorable metabolic features and unhealthy lifestyle habits might at least in part explain this observation. Awareness-raising campaigns might contribute to the identification of individuals at greater need of care, thereby improving the targeted application of pharmacological and nonpharmacological cardiovascular prevention strategies.

Acknowledgements The authors would like to acknowledge the work of all the pharmacists who collected the data during the campaign, and the contribution of Teva, Omron, and Corman. We acknowledge the "Alberto Zanchetti" memorial scholarship 2018, sponsored by Federfarma and granted to MDF on the occasion of the XXXII National Conference on Hypertension - Italian Society of Hypertension, Rome (Italy), September 27th, 2018. The scholarship had no involvement in collection, analysis, and interpretation of data, in writing the report, and in the decision to submit the article for publication. The Italian Society of Hypertension: Board of Directors: Prof. Guido Grassi, current President; Prof. Claudio Ferri, past President; Prof. Maria Lorenza Muiesan, vice President; Prof. Massimo Salvetti, secretary; Dr. Leonardo Sechi, bursar; board members: Prof. Arrigo F.G. Cicero, Prof Guido Iaccarino, Prof. Pietro Minuz, Prof. Paolo Mulatero, Prof. Giuseppe Mulè, Prof. Giacomo Pucci, Prof. Carmine Savoia. Scientific Committee: Prof. Claudio Borghi, Prof. Massimo Volpe.

Author contributions MDF contributed to data acquisition and manuscript drafting. RDP analyzed and interpreted the data, wrote the first draft, and reviewed/edited the manuscript. SP contributed to data acquisition and manuscript drafting. DG contributed to data acquisition and manuscript drafting. CF was responsible for conceptualization, interpretation of data, and reviewed/edited the manuscript. All the authors have read and approved the final version of the manuscript.

Funding Open access funding provided by Università degli Studi dell'Aquila within the CRUI-CARE Agreement.

\section{Declarations}

Conflicts of interest The Authors declare no conflicts of interests.

Ethics approval The survey fulfills the principles stated in the Declaration of Helsinki, it was entirely observational, and ethics approval was not required.

Consent to participate Participation was completely voluntary, and signed informed consent was obtained from each participant at enrollment.
Consent for publication Consent to participation included permission to use aggregated, anonymized data for scientific divulgation purposes. Data were identified at enrollment, and identification of participants was therefore not possible.

Availability of data and material Data could be made available upon reasonable request to the corresponding author.

Code availability Not applicable.

Open Access This article is licensed under a Creative Commons Attribution-NonCommercial 4.0 International License, which permits any non-commercial use, sharing, adaptation, distribution and reproduction in any medium or format, as long as you give appropriate credit to the original author(s) and the source, provide a link to the Creative Commons licence, and indicate if changes were made. The images or other third party material in this article are included in the article's Creative Commons licence, unless indicated otherwise in a credit line to the material. If material is not included in the article's Creative Commons licence and your intended use is not permitted by statutory regulation or exceeds the permitted use, you will need to obtain permission directly from the copyright holder. To view a copy of this licence, visit http://creativecommons.org/licenses/by-nc/4.0/.

\section{References}

1. Whelton PK, Carey RM, Aronow WS, Casey DE Jr, Collins KJ, Dennison Himmelfarb C, et al. 2017 ACC/AHA/AAPA/ABC/ ACPM/AGS/APhA/ASH/ASPC/NMA/PCNA guideline for the prevention, detection, evaluation, and management of high blood pressure in adults: executive summary: a report of the American College of Cardiology/American Heart Association Task Force on Clinical Practice Guidelines. Circulation. 2018;138:e426-83.

2. de Boer IH, Bangalore S, Benetos A, Davis AM, Michos ED, Muntner P, et al. Diabetes and hypertension: a position statement by the American Diabetes Association. Diabetes Care. 2017:40:1273-84.

3. Chen G, McAlister FA, Walker RL, Hemmelgarn BR, Campbell NRC. Cardiovascular outcomes in framingham participants with diabetes: the importance of blood pressure. Hypertension. 2011;57:891-7.

4. Eaddy MT, Shah M, Lunacsek O, Stanford RH. The burden of illness of hypertension and comorbid diabetes. Curr Med Res Opin. 2008;24:2501-7.

5. American Diabetes Association. Economic Costs of Diabetes in the U.S. in 2017. Diabetes Care. 2018;41: 917-928.

6. NCD Risk Factor Collaboration (NCD-RisC). Long-term and recent trends in hypertension awareness, treatment, and control in 12 high-income countries: an analysis of 123 nationally representative surveys. Lancet. 2019;394:639-51.

7. Tocci G, Nati G, Cricelli C, Parretti D, Lapi F, Ferrucci A, et al. Prevalence and control of hypertension in the general practice in Italy: updated analysis of a large database. J Hum Hypertens. 2017;31:258-62.

8. Tocci G, Nati G, Cricelli C, Parretti D, Lapi F, Ferrucci A, et al. Prevalence and control of hypertension in different macro-areas in italy: analysis of a large database by the general practice. High Blood Press Cardiovasc Prev. 2016;23:387-93.

9. Berlowitz DR, Ash AS, Hickey EC, Glickman M, Friedman R, Kader B. Hypertension management in patients with diabetes: the need for more aggressive therapy. Diabetes Care. 2003;26:355-9. https://doi.org/10.2337/diacare.26.2.355. 
10. Geiss LS, Rolka DB, Engelgau MM. Elevated blood pressure among U.S. adults with diabetes, 1988-19941 1The full text of this article is available via AJPM Online at http://www.elsevier. com/locate/ajpmonline. Am J Prev Med. 2002. 22:42-48. https:// doi.org/10.1016/s0749-3797(01)00399-3

11. de Burgos-Lunar C, de Burgos-Lunar C, Jiménez-García R, Salinero-Fort MA, Gómez-Campelo P, Gil Á, et al. Trends in hypertension prevalence, awareness, treatment and control in an adult type 2 diabetes Spanish population between 2003 and 2009. PLoS ONE. 2014;9:e86713. https://doi.org/10.1371/journal.pone. 0086713.

12. Cummings DM, Letter AJ, Howard G, Howard VJ, Safford MM, Prince V, et al. Generic medications and blood pressure control in diabetic hypertensive subjects: results from the REasons for Geographic And Racial Differences in Stroke (REGARDS) study. Diabetes Care. 2013;36:591-7.

13. Del Pinto R, Pagliacci S, De Feo M, Grassi D, Ferri C, Italian Society of Hypertension and Federfarma. Prevalence of hypertension and associated cardiovascular risk factors among pharmacies customers: an Italian nationwide epidemiological survey. Eur J Prev Cardiol. 2020;27:1228-30.

14. Conroy R. Estimation of ten-year risk of fatal cardiovascular disease in Europe: the SCORE project. Eur Heart J. 2003;24:9871003. https://doi.org/10.1016/s0195-668x(03)00114-3.

15. Williams B, Mancia G, Spiering W, Agabiti Rosei E, Azizi M, Burnier M, et al. 2018 ESC/ESH guidelines for the management of arterial hypertension. Eur Heart J. 2018;39:3021-104.

16. Rizzo ML. Statistical computing with R. Boca Raton: CRC Press; 2007.

17. Lastra G, Syed S, Kurukulasuriya LR, Manrique C, Sowers JR. Type 2 diabetes mellitus and hypertension: an update. Endocrinol Metab Clin N Am. 2014;43:103-22.

18. Tsimihodimos V, Gonzalez-Villalpando C, Meigs JB, Ferrannini E. Hypertension and diabetes mellitus: coprediction and time trajectories. Hypertension. 2018;71:422-8.
19. Muniyappa R, Montagnani M, Koh KK, Quon MJ. Cardiovascular actions of insulin. Endocr Rev. 2007;28:463-91. https://doi.org/ 10.1210/er.2007-0006.

20. Del Pinto R, Pietropaoli D, Munoz-Aguilera E, D’Aiuto F, Czesnikiewicz-Guzik M, Monaco A, et al. Periodontitis and hypertension: is the association causal? High Blood Press Cardiovasc Prev. 2020;27:281-9.

21. Rehman A, Setter SM, Vue MH. Drug-induced glucose alterations part 2: drug-induced hyperglycemia. Diabetes Spectr. 2018;24:234-8. https://doi.org/10.2337/diaspect.24.4.234.

22. Nesto RW, Bell D, Bonow RO, Fonseca V, Grundy SM, Horton ES, et al. Thiazolidinedione use, fluid retention, and congestive heart failure: a consensus statement from the American Heart Association and American Diabetes Association. Diabetes Care. 2004;27:256-63.

23. Arnold SV, Inzucchi SE, Echouffo-Tcheugui JB, Tang F, Lam CSP, Sperling LS, et al. Understanding contemporary use of thiazolidinediones. Circ Heart Fail. 2019. https://doi.org/10.1161/ circheartfailure.118.005855.

24. Chobufo MD, Gayam V, Soluny J, Rahman EU, Enoru S, Foryoung JB, et al. Prevalence and control rates of hypertension in the USA: 2017-2018. Int J Cardiol Hypertens. 2020. https://doi.org/ 10.1016/j.ijchy.2020.100044.

25. Muli S, Meisinger C, Heier M, Thorand B, Peters A, Amann U. Prevalence, awareness, treatment, and control of hypertension in older people: results from the population-based KORA-age 1 study. BMC Public Health. 2020;20:1049.

26. Pietropaoli D, Monaco A, D’Aiuto F, Muñoz Aguilera E, Ortu $\mathrm{E}$, Giannoni M, et al. Active gingival inflammation is linked to hypertension. J Hypertens. 2020. https://doi.org/10.1097/HJH. 0000000000002514.

27. Del Pinto R, Wright JT, Monaco A, Pietropaoli D, Ferri C. Vitamin D and blood pressure control among hypertensive adults: results from NHANES 2001-2014. J Hypertens. 2020;38:150-8.

\section{Authors and Affiliations}

\section{Martina De Feo ${ }^{1} \cdot$ Rita Del Pinto $^{1}$ (1) . Silvia Pagliacci ${ }^{2} \cdot$ Davide Grassi $^{1} \cdot$ Claudio Ferri $^{1}$ on behalf of The Italian Society of Hypertension and Federfarma}

1 Hypertension and Cardiovascular Prevention Unit, Division of Internal Medicine and Nephrology, Department of Life, Health and Environmental Sciences, San Salvatore Hospital, University of L'Aquila, Building Delta 6, Coppito, 67100 L'Aquila, Italy
2 Sunifar, Federfarma, Rome, Italy 